Article

\title{
Functional Ingredients Extraction from Garcinia mangostana Pericarp by Liquefied Dimethyl Ether
}

\author{
Hazuki Nerome ${ }^{1}$, Rintaro Hoshino ${ }^{2}$, Shota Ito $^{1}$, Ryohei Esaki ${ }^{1}$, Yuki Eto ${ }^{1}$, \\ Shion Wakiyama ${ }^{1}$, Tanjina Sharmin ${ }^{1}$, Motonobu Goto ${ }^{2}$, Hideki Kanda ${ }^{2,3}$, and \\ Kenji Mishima ${ }^{1, *}$
}

1 Department of Chemical Engineering, Fukuoka University, Jonan, Fukuoka 814-0180, Japan 2 Department of Chemical Engineering, Nagoya University, Chikusa, Nagoya 464-8603, Japan 3 Japan Science and Technology Agency, Kawaguchi, Saitama 332-0012, Japan

E-mail: *mishima@fukuoka-u.ac.jp (Corresponding author)

\begin{abstract}
The mangosteen (Garcinia mangostana Linn.) pericarp contains rich xanthone, a one kind of the polyphenols in the non-edible portion. In recent years, xanthones have been noted as a functionality such as anti-cancer effect and is expected as pharmaceuticals and health supplements. In this work, extraction of xanthones from mangosteen pericarp by using liquefied DME were investigated. Wet powder and cube samples were used as a raw material. Experimental conditions were $35{ }^{\circ} \mathrm{C}, 0.8 \mathrm{MPa}$ with various amounts of sample (1, 3, $6 \mathrm{~g})$. Extracted components were analyzed by using high performance liquid chromatography (HPLC). As a result, it was confirmed that eight kinds of xanthones such as alpha-mangostin, 3-Isomangostin, Mangostanol, 8-Desoxygartanin, Gartanin, Garcinone E, 9-Hydroxycalabaxanthone, beta-Mangostin were extracted. The highest yield of alpha-mangostin ( $42.9 \mathrm{mg} / \mathrm{g}$ _dry sample) was obtained with a powder sample of $6 \mathrm{~g}$ loaded. Final alpha-magostin corresponded to about $104 \%$ of the ethanol extraction with wet mangosteen pericarp, and $72 \%$ of the dried sample. Therefore, it was considered that in the extraction of xanthones from the mangosteen, liquefied DME extraction was valid.
\end{abstract}

Keywords: Liquefied dimethyl ether, Garcinia mangostana, xanthones, extraction.

ENGINEERING JOURNAL Volume 20 Issue 4

Received 3 March 2016

Accepted 13 June 2016

Published 1 August 2016

Online at http://www.engj.org/

DOI:10.4186/ej.2016.20.4.155 


\section{Introduction}

Mangosteen (Garcinia mangostana Linn.) is one of the tropical fruits belonging to the Guttiferae family which called "queen of the fruit" because of its sweet juicy edible part. It is grow in Thailand, Malaya, India, Vietnam, Singapore, Philippines and Burma [1-2]. It has a dark red pericarp that has been discarded. However, the valuable compounds such as xanthones, which is a kind of polyphenols are contained in the pericarp. Xanthones are attracting attention as a dietary supplement and a medicament because its powerful functionalities [3-6]. In recent years, the functionality of xanthones has been reported on medical, pharmaceutical and food science fields as follow. Antiproliferative, antioxidation and induction of apoptosis by mangosteen extract on human breast cancer cell line [7-9]. Induction of apoptosis by xanthones occurred in human leukemia cell lines[10]. Garcinone E, one of a xanthone derivatives, has potent cytotoxic effect against liver cancer, gastric cancer, lung cancer and colorectal cancer [11, 12]. Currently, the organic solvent (ethanol, methanol and ethyl acetate, etc.) were used as conventional extraction solvents for obtaining the xanthones $[2,7,12]$. However, the following problems have been concerned; the oxidation and thermal denaturation, the environmental impact, and effects on the human body of residual solvent. As a method of solving these problems, supercritical carbon dioxide $\left(\mathrm{SC}-\mathrm{CO}_{2}\right)$ and liquefied dimethyl ether (DME) are receiving attention as the extraction solvent because of their useful properties. $\mathrm{SC}-\mathrm{CO}_{2}$ is excellent extraction solvent for the non-polar substance because it has properties similar to hexane. Additionally the method has shown high selectivity by operating conditions such as temperatures and pressures [13-15]. However, it is necessary to use a special apparatus to establish the high pressure of SC$\mathrm{CO}_{2}$ and pretreatment such as sample drying. In the case of DME, the standard boiling point is $-24.8{ }^{\circ} \mathrm{C}$, and its saturated vapor pressure at $20^{\circ} \mathrm{C}$ is $0.51 \mathrm{MPa}$. Because of the weak hydrogen bonds of DME, water dissolves into the liquefied DME to the extent of $7-8 \mathrm{wt} \%$ at room temperature. Therefore, those characteristic properties, it can extract functional ingredients from the high moisture content raw materials at the vicinity of room temperature [16-23]. Additionally, DME has been approved as a safe extraction solvent for the production of foodstuffs and food ingredients by the European Food Safety Authority [24]. In this work, the alpha-mangostin which is a kind of xanthone would be extracted from the raw pericarp of mangosteen using liquefied DME. Experimental conditions were $35^{\circ} \mathrm{C} / 0.8 \mathrm{MPa}$ and extracted components were analyzed by using high performance liquid chromatography (HPLC).

\section{Experimental}

\subsection{Material and Chemicals}

For the extraction, pericarp of mangosteen which was cultivated in Thailand was used. Wet sample of pericarps was prepared as powder type $(0.5-1.0 \mathrm{~mm})$ and cube type $(5 \mathrm{~mm})$. alpha-Mangostin was purchased from Wako Co. Ltd., Japan was used for standard. Other xanthones (3-Isomangostin, Mangostanol, 8-Desoxygartanin, Gartanin, Garcinone E, 9-Hydroxycalabaxanthone, beta-Mangostin) were calculated using the calibration curve of alpha-mangostin. HPLC-grade of methanol and acetic acid used for HPLC analysis. The analytical-grade of ethanol which used for ethanol extraction and dilution solvent were purchased from Wako Co. Ltd., Japan.

\subsection{Equipment and Procedures}

\subsubsection{DME Extraction}

Figure 1 shows a schematic of the laboratory-scale DME extraction apparatus. Liquefied DME tank (100 ml; TVS-1-100, Taiatsu Techno Corp., Saitama, Japan), the extraction column (10 ml; HPG-10-5, Taiatsu Techno Corp., Saitama, Japan) and collector (96 ml; HPG-96-3, Taiatsu Techno Corp., Saitama, Japan) were employed for the experiment. 


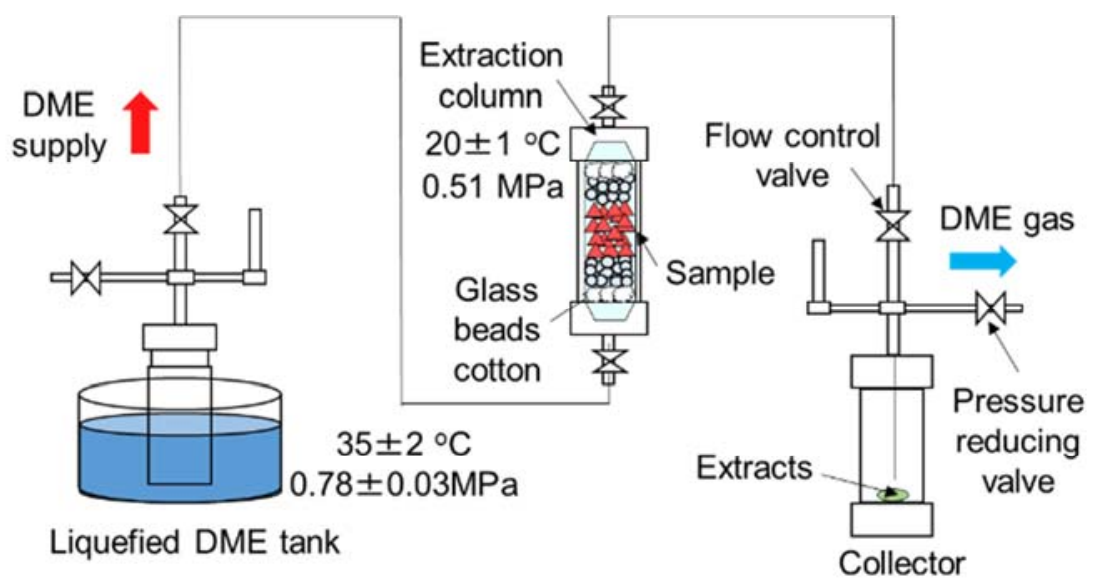

Fig.1. Schematic diagram of DME extraction apparatus.

Raw materials were prepared for powder type (moisture content of 61.6\%) and cube type (moisture content of $62.9 \%$ ). In each experiment, approximately 1, 3, and $6 \mathrm{~g}$ of wet samples were loaded into the extraction column and the remaining volume was filled with glass beads (diameter between 1.5 and $2.5 \mathrm{~mm}$; BZ-2, ASONE Co., Inc., Osaka, Japan) and cotton at the bottom and top of the column $[18,25]$.

The liquefied DME in the tank was controlled at $35 \pm 2{ }^{\circ} \mathrm{C}$ in a water bath, while the saturated vapor pressure of DME in the tank was $0.78 \pm 0.03 \mathrm{MPa}[16]$. The liquefied DME was supplied to the extraction column, and cooled down to room temperature using the long tube, which connected the tank and the extraction column. The temperature of the DME in the tube and extraction column was $20 \pm 1^{\circ} \mathrm{C}$. DME flowed owing to the pressure difference between tank and the extraction column while the DME flow rate was maintained at $7 \mathrm{~mL} / \mathrm{min}$ using a pressure-reducing valve in the outlet of the extraction column. After the liquefied DME was passed through the extraction column at different time intervals, the DME was evaporated by opening the pressure-reducing valve of collector. The amount of the total extracts remaining in collector was equal to the total amount of extract and water extracted from the samples. The total extract was weighed after collection, and the yield of water, extract, and xanthones were determined using the equation shown below (1), (2), and (3). In addition, the amount of alpha-mangostin in the extract was analyzed using high-performance liquid chromatography (HPLC).

$$
\begin{gathered}
\text { Yield of water }=\frac{\text { Extracted water }[\mathrm{g}]}{\text { Initial amount of water in samples }[\mathrm{g}]} \\
\text { Yield of extract }=\frac{\text { Extracts }[\mathrm{g}]}{\text { Dry samples }[\mathrm{g}]} \\
\text { Yield of xanthone }=\frac{\text { Extracted xanthone }[\mathrm{mg}]}{\text { Dry samples }[\mathrm{g}]}
\end{gathered}
$$

\subsubsection{Conventional Method Using Ethanol as Extraction Solvent}

Ethanol extraction for comparison was performed. Powder type $(0.5-1.0 \mathrm{~mm})$ was used as an extraction material in wet sample (moisture content of 61.6\%) and dry sample (moisture content of 5.3\%). Using a batch extractor, $100 \mathrm{~mL}$ ethanol was heated while mixing on a hot stirrer $(500 \mathrm{rpm})$ at $35^{\circ} \mathrm{C}$ and ambient pressure. A sample of milled mangosteen pericarp $(1.0 \mathrm{~g})$ was added when the pre-treatment temperature condition was achieved, then the extraction was started. $1 \mathrm{~mL}$ extract liquid was collected at 10, 20, 30, 60, and $90 \mathrm{~min}$. 


\subsection{HPLC Analysis}

The HPLC system consisted of a Tosoh LC-8010 system (Tosoh Co. Japan) which equipped with a UV detector. The extracts including xanthones were separated using a TSK-GEL (Tosoh Co. Japan) ODS-80Ts column $(150 \times 4.6 \mathrm{~mm})$ at $40{ }^{\circ} \mathrm{C}$. The detection wavelength was set at $340 \mathrm{~nm}$. Extracts were dissolved in $4 \mathrm{~mL}$ of ethanol and injected into the HPLC system. The injection volume was 5 or $50 \mu \mathrm{L}$, which was selected based on the extract concentration to avoid detector saturation. Two mobile phases were used during the separations: (A) methanol and (B) $0.1 \%$ acetic acid in water. The methanol gradient profiles were as follows: $75 \%$ over $0-10 \mathrm{~min} ; 90 \%$ over $50-60 \mathrm{~min} ; 75 \%$ over $60-70 \mathrm{~min}$. The flow rate was set at $0.8 \mathrm{~mL} / \mathrm{min}$.

\section{Result and Discussion}

DME extraction for the wet sample of mangosteen pericarp was successfully carried out. Fig. 2 shows the pictures of raw material, residue, and extracts which dissolved in ethanol after DME extraction. The color of the raw material was dark red-purple, however the color of the residue was bleached to orange-yellow. On the other hand, the color of the initial extract was orange, the extract gradually lost its color with increasing extraction time because of the consumption of solvent towards the end of the extraction process.

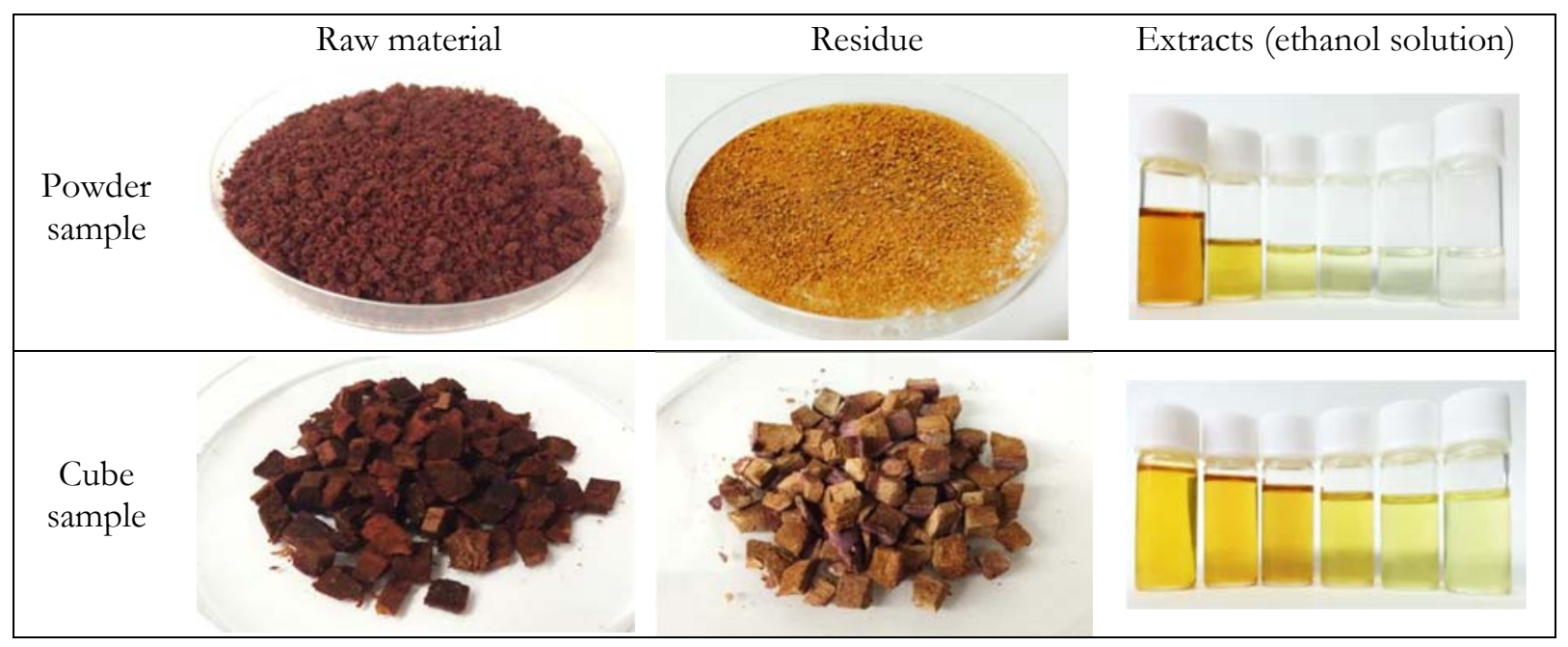

Fig. 2. Images of raw material, residue, and extracts.

\subsection{Water Extraction}

Figure 3 shows the amounts of water removal from the samples using liquefied DME. In order to differing water contents in each sample, the DME consumption (horizontal axis) was expressed as the ratio between the consumption of DME and the total initial amount of water in the tested sample. In the case of shape of the sample, the extracted water from cube sample was slightly lower than the powder type due to its thickness [16]. Moreover, higher amount of DME was required to extract the same amount of water compared to powder type. On the other hand, in the case of powder sample, extraction equilibrium has been nearly reached in the initial stage. Therefore, it is considered that the DME consumption maybe reduced by milling in order to increase the contact area. In the case of extraction using various filling amounts, 6 and $3 \mathrm{~g}$ are obtained almost the same amount of water $(0.8 \mathrm{~g} / \mathrm{g}$ initial water). $1 \mathrm{~g}$ was the lowest yield $(0.6 \mathrm{~g} / \mathrm{g}$ initial water) due to some of the extract may remain in the inside of the tube of the apparatus. Therefore, it may be considered that in the case of a small amount of filling, loss of the extract is increased. 


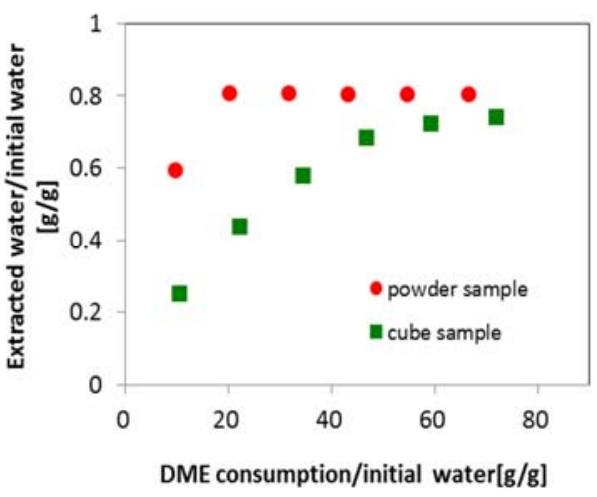

(a)

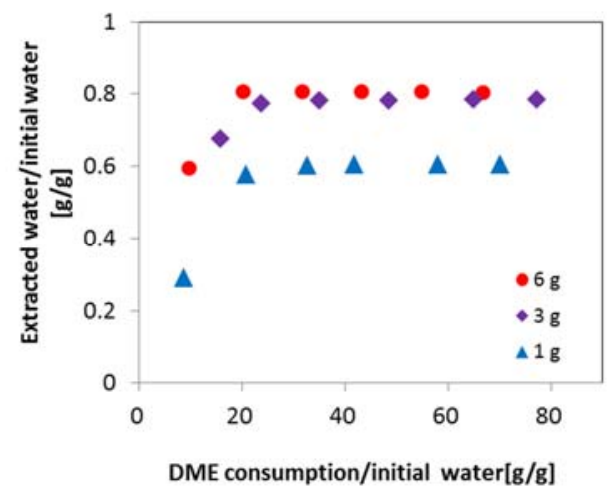

(b)

Fig.3. Dewatering rates of mangosteen pericarp obtained by DME extraction. (a) Different sample shape, (b) Various filling amount.

\subsection{Yield of Extract and Xanthones}

The yield of extracted components and xanthones by DME extraction from powder sample and cube sample with various filling amounts were investigated. The yield of extracted xanthones by DME and ethanol extraction were shown in Table 1.

Table 1. Experimental condition with yield of extracted xanthones $\left[\mathrm{mg} / \mathrm{g} \_\right.$dry sample].

\begin{tabular}{lcccccc}
\hline Extraction solvent & \multicolumn{4}{c}{ DME } & \multicolumn{3}{c}{ Ethanol } \\
\hline Sample type & cube & powder & powder & powder & powder & powder \\
& wet & wet & wet & wet & wet & dry \\
Filling amount $[\mathrm{g}]$ & 6 & 6 & 3 & 1 & 1 & 1 \\
\hline Various xanthones & & & & & & \\
3-Isomangostin & 0.268 & 0.490 & 0.486 & 2.958 & - & 0.736 \\
Mangostanol & 0.574 & 1.098 & 0.828 & 1.776 & - & 0.731 \\
8-Desoxygartanin & 5.500 & 6.319 & 6.815 & 25.144 & 5.668 & 11.479 \\
Gartanin & 0.794 & 2.073 & 2.420 & 7.973 & 1.089 & 3.971 \\
alpha-Mangostin & 33.322 & 42.885 & 40.783 & 17.453 & 41.140 & 59.657 \\
Garcinone E & 1.065 & 1.778 & 1.359 & 5.056 & 2.126 & 1.851 \\
9-Hydroxycalabaxanthone & 0.829 & 1.141 & 1.062 & 4.222 & 0.499 & 1.330 \\
beta-Mangostin & 0.471 & 0.693 & 0.722 & 2.805 & 0.773 & 0.889 \\
\hline
\end{tabular}

Figures 4 and 5 show the yields of extracted components and alpha-mangostin as xanthone derived compounds. In the case of cube sample, the yields of extracted components and alpha-mangostin were lower than powder samples even though it had almost the same yield of water. There are possible reasons that the water does not act as a co-solvent because the solubility of xanthone in water is low [26]. Therefore, it can be considered that preferentially water has been extracted. However, the cube type allows to recover alpha-mangostin of $33.3 \mathrm{mg} / \mathrm{g}$ _dry sample (about $80 \%$ of the powder sample) without milling. Cube type has advantages during the extraction such as to avoid the milling process and it can be easily handling of the sample. On the other hand, in the case of extraction using various filling amount, similar tendency as the extraction of water was obtained. At 6 and $3 \mathrm{~g}$ sample loaded, almost the same amount of extracts and alpha-mangostin are obtained. However, the lowest yield was extracted at $1 \mathrm{~g}$ sample loaded. Similar results were also found in the water extraction. The loss of the extract increased when the small amount of sample was loaded in the extractor. 
The maximum recovered of alpha-magostin could approach to $45 \mathrm{mg} / \mathrm{g}$-sample from $6 \mathrm{~g}$ powder sample. It is corresponding to about $104 \%$ of the ethanol extraction with wet mangosteen pericarp, and $72 \%$ of the dried sample.

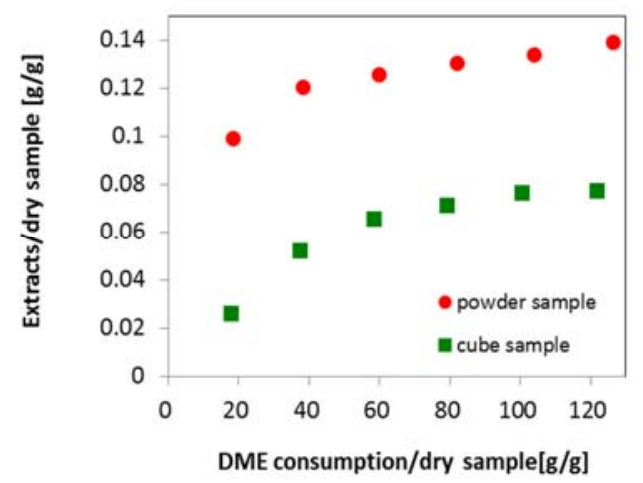

(a)

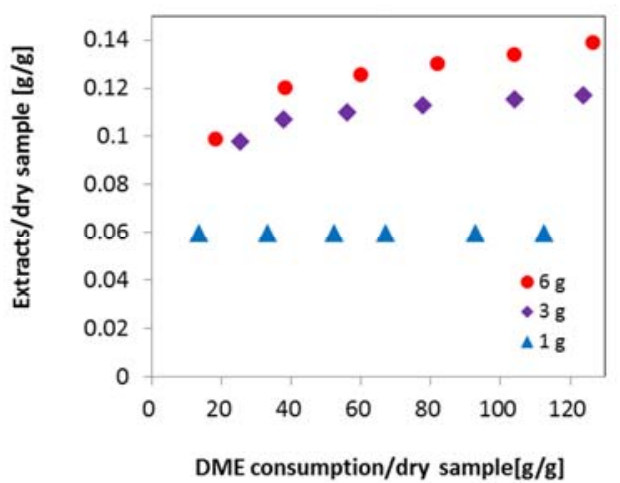

(b)

Fig. 4. Amount of extracts from mangosteen pericarp by DME extraction. (a) Different sample shape, (b) Various filling amount.

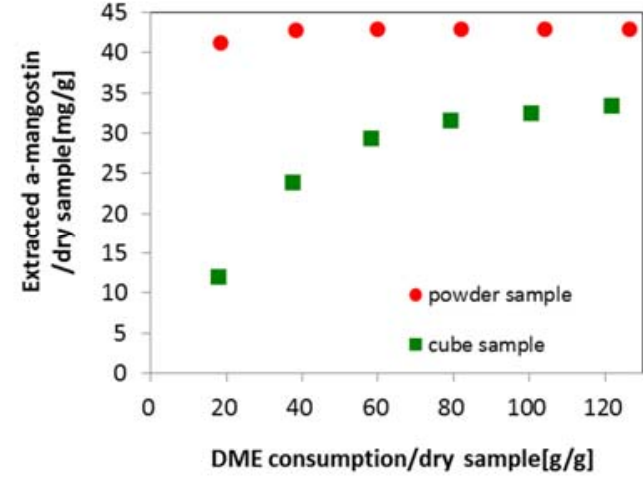

(a)

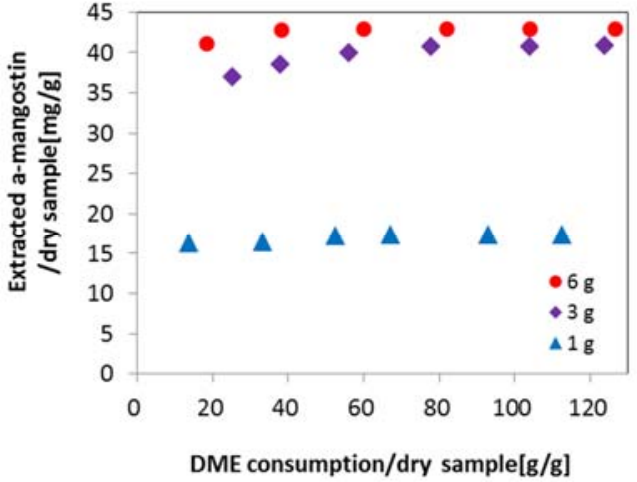

(b)

Fig.5. Amount of extracted alpha-mangostin from mangosteen pericarp by DME extraction. (a) Different sample shape, (b) Various filling amount.

\section{Conclusion}

In this work, the liquefied DME extraction method was verified that can be used to extract water, extract and xanthone from the wet mangosteen pericarp. Final extracted yield of water from the cube sample was almost equal compared with the powder type $(0.8 \mathrm{~g} / \mathrm{g}$-initial water $)$. However, in the case of powder sample, extraction equilibrium has been nearly reached in the initial stage. The different of water yield seemed depend on the filling amount of sample. The small amount of filling resulted the loss of the extract increased. The highest yield of extract $\left(0.14 \mathrm{~g} / \mathrm{g} \_\right.$dry sample) and alpha-mangostin ( $42.9 \mathrm{mg} / \mathrm{g} \_$dry sample) were obtained with a powder sample of $6 \mathrm{~g}$ filling amount.

\section{References}

[1] R. Zadernowski, S. Czaplicki, and M. Naczk, "Phenolic acid profiles of mangosteen fruits (Garcinia mangostana)," Food Chem., vol. 112, no. 3, pp. 685-689, June, 2009.

[2] J. Pedraza-Chaverri, N. Cárdenas-Rodríguez, M. Orozco-Ibarra, and J. M. Pérez-Rojas, "Medicinal properties of mangosteen (Garcinia mangostana)," Food Chem. Toxicol., vol. 46, no. 10, pp. 3227-3239, Oct, 2008. 
[3] A. S. Zarena and K. Udaya Sankar, "Xanthones enriched extracts from mangosteen pericarp obtained by supercritical carbon dioxide process," Sep. Purif. Technol., vol. 80, no. 1, pp. 172-178, July, 2011.

[4] A. S. Zarena and K. Udaya Sankar, "Supercritical carbon dioxide extraction of xanthones with antioxidant activity from Garcinia mangostana: Characterization by HPLC/LC-ESI-MS," J. Supercrit. Fluids, vol. 49, no. 3, pp. 330-337, July, 2009.

[5] Y. Akao, Y. Nakagawa, M. Iinuma, and Y. Nozawa, "Anti-cancer effects of xanthones from pericarps of mangosteen," Int. J. Mol. Sci., vol. 9, no. 3, pp. 355-370, Mar, 2008.

[6] A. F. A. Aisha, K. M. Abu-Salah, Z. Ismail, and A. Majid, "In vitro and in vivo anti-colon cancer effects of Garinia mangostana xanthones extract," BMC Complementary and Alternative Medicine, vol. 12. p. 104, July, 2012.

[7] P. Moongkarndi, N. Kosem, S. Kaslungka, O. Luanratana, N. Pongpan, and N. Neungton, "Antiproliferation, antioxidation and induction of apoptosis by Garcinia mangostana (mangosteen) on SKBR3 human breast cancer cell line," J. Ethnopharmacol., vol. 90, no. 1, pp. 161-166, Sep, 2004.

[8] M. J. Balunas, B. Su, R. W. Brueggemeier, and a. D. Kinghorn, "Xanthones from the botanical dietary supplement mangosteen (Garcinia mangostana) with aromatase inhibitory activity," J. Nat. Prod., vol. 71, no. 7, pp. 1161-1166, Jul, 2008.

[9] H. Doi, M. A. Shibata, E. Shibata, J. Morimoto, Y. Akao, M. Iinuma, N. Tanigawa, and Y. Otsuki, "Panaxanthone isolated from pericarp of Garcinia mangostana L. suppresses tumor growth and metastasis of a mouse model of mammary cancer," Anticancer Res., vol. 29, no. 7, pp. 2485-2495, Jul, 2009.

[10] K. Matsumoto, Y. Akao, E. Kobayashi, K. Ohguchi, T. Ito, T. Tanaka, M. Iinuma, and Y. Nozawa, "Induction of apoptosis by xanthones from mangosteen in human leukemia cell lines," J. Nat. Prod., vol. 66, no. 8, pp. 1124-1127, Aug, 2003.

[11] C. K. Ho, Y. L. Huang, and C. C. Chen, "Garcinone E, a xanthone derivative, has potent cytotoxic effect against hepatocellular carcinoma cell lines," Planta Med., vol. 68, no. 11, pp. 975-979, Nov, 2002.

[12] V. Nabandith, M. Suzui, T. Morioka, T. Kaneshiro, T. Kinjo, K. Matsumoto, Y. Akao, M. Iinuma, and N. Yoshimi, "Inhibitory effects of crude alpha-mangostin, a xanthone derivative, on two different categories of colon preneoplastic lesions induced by 1, 2-dimethylhydrazine in the rat," Asian Pac J Cancer Prev., vol. 5, no. 4, pp. 433-438, Dec, 2004.

[13] H. Nerome, S. Machmudah, A. T. Quitain, M. Sasaki, and M. Goto, "Supercritical Carbon Dioxide Extraction of Carotenoids From Momordica Cochinchinensis," J. Sci. Technol., vol. 49, no. 5A, pp. 177183, Oct, 2011.

[14] K. Mishima, R. Kawakami, H. Yokota, T. Harada, T. Kato, H. Kawamura, K. Matsuyama, S. Mustofa, F. Hasanah, Y. D. nayati Siregar, L. S. E. Putri, and A. Salim, "Extraction of Luteolin and Apigenin from Leaves of Perilla frutescens (L.) Britt. with Liquid Carbon Dioxide," Solvent extracion Res. Dev. Japan, vol. 21, no. 1, pp. 55-63, 2014.

[15] K. Mishima, H. Kawamura, S. Ito, Y. Inoue, T. Hirota, T. Kato, T. Sharmin, R. Kawakami, K. Irie, K. Mishima, T. Harada, S. Mustofa, F. Hasanah, Y. Dian, I. Siregar, L. Surayya, E. Putri, and A. Salim, "Liquid Carbon Dioxide Extraction of Xanthones from the Pericarps of Garcinia Mangostana Linn. Enhanced by Ultrasonic Irradiation," Solvent extracion Res. Dev. Japan, vol. 22, no. 2, pp. 187-199, 2015.

[16] R. Hoshino, S. Machmudah, H. Kanda, and M. Goto, "Simultaneous Extraction of Water and Essential Oils from Citrus Leaves and Peels Using Liquefied Dimethyl Ether," J. Nutr. food Sci., vol. 4, no. 5, Aug, 2014.

[17] M. Goto, H. Kanda, Wahyudiono, and S. Machmudah, "Extraction of carotenoids and lipids from algae by supercritical $\mathrm{CO}_{2}$ and subcritical dimethyl ether," J. Supercrit. Fluids, vol. 96, pp. 245-251, Jan, 2015.

[18] P. Boonnoun, Y. Kurita, Y. Kamo, S. Machmudah, Y. Okita, E. Ohashi, and H. Kanda, "Wet extraction of lipids and astaxanthin from Haematococcus pluvialis by liquefied dimethyl ether," J. Nutr. Food Sci., vol. 4, no. 5, p. 1000305, Aug, 2014.

[19] J. Wu, Y. Zhou, and E. W. Lemmon, "An Equation of State for the Thermodynamic Properties of Dimethyl Ether," J. Phys. Chem. Ref. Data, vol. 40, Jun, 2011.

[20] K. Oshita, S. Toda, M. Takaoka, H. Kanda, T. Fujimori, K. Matsukawa, and T. Fujiwara, "Solid fuel production from cattle manure by dewatering using liquefied dimethyl ether," Fuel, vol. 159, pp. 7-14, Nov, 2015.

[21] P. Li, H. Kanda, and H. Makino, "Simultaneous production of bio-solid fuel and bio-crude from vegetal biomass using liquefied dimethyl ether," Fuel, vol. 116, pp. 370-376, Jan, 2014. 
[22] H. Kanda, P. Li, and H. Makino, "Production of decaffeinated green tea leaves using liquefied dimethyl ether," Food Bioprod. Process., vol. 91, no. 4, pp. 376-380, Oct, 2013.

[23] H. Kanda, P. Li, T. Yoshimura, and S. Okada, "Wet extraction of hydrocarbons from Botryococcus brannii by dimethyl ether as compared with dry extraction by hexane," Fuel, vol. 105, pp. 535-539, Mar, 2013.

[24] A. Anadón, D. Bell, M. Binderup, W. Bursch, L. Castle, K. Engel, R. Franz, N. Gontard, T. Haertlé, T. Husøy, K. Jany, C. Leclercq, J. Lhuguenot, W. Mennes, M. Rosaria, K. Pfaff, K. Svensson, F. Toldrá, R. Waring, and D. Wölfle, "Safety in use of dimethyl ether as an extraction solvent," Eur. Food Saf. Auth., vol. 984, pp. 1-13, 2009.

[25] H. Kanda, P. Li, T. Ikehara, and M. Yasumoto-Hirose, "Lipids extracted from several species of natural blue-green microalgae by dimethyl ether: Extraction yield and properties," Fuel, vol. 95, pp. 8892, May, 2012.

[26] K. Chhouk, A. T. Quitain, P. D. Gaspillo, J. B. Maridable, M. Sasaki, Y. Shimoyama, and M. Goto, "Supercritical Carbon Dioxide-Mediated Hydrothermal Extraction of Bioactive Compounds from Garcinia mangostana Pericarp," J. Supercrit. Fluids. 2015, In Press. 